\title{
Developing Car Sharing to Promote an Automobile Power Strategy
}

\author{
Qiao Yingjun ${ }^{1}$, Ji Xuehong ${ }^{2}$ \\ 1. The CAE Centre for Strategic Studies, Beijing 100088, China \\ 2. School of Economics and Management, North China University of Technology, Beijing 100144, China
}

\begin{abstract}
This study briefly introduces the present situation and the prospects of the development of car sharing at home and abroad. Combining new features such as low carbonization, electrification, networking, intelligence, and sharing in the current stage of automobile development, this study aims to explain the influence of car sharing in the promotion of automobile transformation. In addition, this study maintains that Chinese government should attach importance to car sharing from the strategic perspective of automobile power, and create a favorable development environment to promote rapid development of car sharing in China.
\end{abstract}

Keywords: car sharing; automobile power; problem; policy

\section{Car sharing represents a prospective travel mode}

Sharing economy is a time-honored economic arrangement. Written by Feng Menglong (1574-1646), a vernacular writer and poet in China's Ming Dynasty, Records of the States in the Eastern Zhou Dynasty contends that people should share the material and financial resources they subsist on, with others. This gives expression to an ideal state of sharing economy [1]. Due to the limited socioeconomic, scientific and technological levels in society, the idea of the sharing economy remained underdeveloped for a long period of time. Over the years, the world has witnessed extraordinary advancements through the information revolution, extensive application of all kinds of information and communication technologies, the emergence of platform economy, and the rapid popularization of mobile Internet. All of these things have been beneficial in the integration of various scattered resources, identifying diverse market needs, and attaining a quick match between supply and demand information. Today, the sharing economy is rapidly developing and overturning the traditional economic pattern in a revolutionary manner.
Primarily characterized by sharing based on the right to use, the sharing economy in China refers to the sum of economic activities in which the massive and scattered resources are integrated to satisfy the diverse needs of people using modern information technologies, such as the internet.

The concept of sharing economy is rapidly penetrating into different walks of life. In this regard, the most typical case is the advent of urban bike sharing. In mid-2016, sharing of bikes like Mobike and ofo gained popularity rapidly in China's big cities. Within a short period of more than a year, bike sharing emerged suddenly, and attained great popularity rapidly. Now, shared bikes can be seen in the streets and alleyways throughout large and medium-sized cities in China. Today, bike sharing has entered the list of the "Four New Inventions" together with highspeed rail, Alipay, and online shopping. It offers an effective solution to traffic linkage for the "last kilometer" and brings about great convenience in the movement of people.

Car sharing is believed to be among the best applications of the next generation sharing economy. Car sharing is rich in its scope and content. It covers not only the right to use car products (namely, the shared cars), but also the sharing of R\&D,

Received date: January 18, 2018; Revised date: February 10, 2018

Corresponding author: Ji Xuehong, School of Economics and Management, North China University of Technology, Professor. Major research fields include car sharing, and business model. E-mail: jixuehong86@163.com

Funding program: CAE Advisory Project “Research on Automobile Power Strategy”(2015-XZ-36)

Chinese version: Strategic Study of CAE 2018, 20 (1): 120-126

Cited item: Qiao Yingjun et al. Developing Car Sharing to Promote an Automobile Power Strategy. Strategic Study of CAE, https://doi.org/10.15302/ J-SSCAE-2018.01.017 
production, manufacture, and sale, and even the sharing of infrastructure, policy environment, and car culture. Car sharing herein mainly refers to the sharing of the right to use cars and car products. Time-sharing lease is a typical application of car sharing. It overcomes the limitations of traditional car leases effectively and reduces the lease time from days to hours and even minutes, thereby significantly increasing the convenience and flexibility of car use.

The combination of shared cars and electric automobiles is universally believed to be the best solution to urban traffic in the future. This combination is of great significance in reducing trip costs and relieving various car-related social problems (for example, traffic jams). Shared car users only need to pay the charge for the use of the car, instead of fixed input and maintenance costs in the later period, thereby reducing their trip costs. While more and more operators are setting foot in car sharing, and more and more operating points are being put in place, an increasing number of cars are available for sharing, thereby improving people's travel efficiency and reducing their travel time. According to the statistical analysis of Shanghai's Evcard cars, the advantage of Evcard in travel efficiency has accelerated the users' behavior of car selling. Specifically, $60 \%$ of Evcard users sold their cars within three months after registration with Evcard, $75 \%$ of Evcard users sold their cars within six months after registration with Evcard, and $35 \%$ of car-buying Evcard users postponed their car-buying behavior. Evidently, car sharing plays an important role in reducing the number of cars on the road. Moreover, car sharing is also of great significance in the mitigation of energy consumption and air pollution.

Many researchers believe that car sharing will be highly popular and will become the main mode of travel in the future. As mentioned in the Analysis and Forecast Report on the Car sharing Market of China in 2018 released by Roland Berger, the direct demand for car sharing in China will grow rapidly from 8160000 times per day (2015) to 37000000 times per day (2018). The corresponding market scale is supposed to increase from 66 billion yuan per year to 380 billion yuan per year, and the potential market scale from the potential demand is expected to reach 1.8 trillion yuan [2]. KPMG predicts that the demand for private cars by people in the US will decrease by at least $50 \%$ due to car sharing in 2030.

\section{Developments in car sharing in China and abroad}

Car sharing originally began in Europe and America. In 1948, the earliest car sharing project emerged in Switzerland. This is generally believed to be the point of origin of modern car sharing. In the 21 st century, car sharing gradually gained popularity as a new business pattern in some countries. Today, car sharing is developing rapidly in Europe and America, and is gradually spreading across the world.

\subsection{Car sharing in the US}

In the US, car sharing began rather early on. Zipcar, the acknowledged first car sharing company in modern times, was set up in Cambridge, Massachusetts, in 2000. By the end of 2017, only a few car sharing companies (including Zipcar, Car2go, and Hertz) have survived several rounds of large-scale mergers and acquisitions in the US car sharing industry. Zipcar, Car2go, and Hertz are all asset-heavy companies that are engaged in time-sharing leases, and their market shares jointly account for $90 \%$ of the entire car sharing market in the US. Turo and Getaround are asset-light companies that run on a peer-to-peer (P2P) basis and charge lower rentals than time-sharing leases. The asset-light mode is characterized in that all cars registered on their platforms are private cars, there are no fixed stop stations available for shared cars, and the types of shared cars are not unified. Statistics from the US Association of Sharing Economy show that sharing one car will lead to a decrease in car purchases, to the extent of 13 cars. According to data released by MIT's Computer Science and Artificial Intelligence Laboratory (CSAIL), 3000 shared cars are enough to replace 13,000 taxies in New York City [3].

\subsection{Car sharing in Germany}

In Germany, car sharing originated in the early 21 st century. In 2008, the Daimler Group carried out the Car2go project on the basis of use on demand, instant lease and return, and charge by minutes. The Car2go project proved to be a great success. By the end of 2017, Car2go formed car fleets in more than 20 cities (including Chongqing in China) across the world and gained more than 2000000 registered members. Car sharing developed very rapidly in Germany. By January 1, 2017, there were 150 car sharing service providers, 600 towns and/or villages that were covered by car sharing, and as many as 1715000 users of car sharing facilities[3].

At present, there are two main car sharing modes operating in Germany. The first is "basic station sharing," whereby, shared cars are parked in basic stations, and users need to take the cars from the basic stations and return them after use. The advantage of this mode lies in the ease of management, while the disadvantage lies in its inconvenience. This mode was adopted by companies like Stadtmobil and Cambio. The second operating mode is "free floating car sharing," which gained popularity quickly in big cities in Germany. Here, users can look for cars available near them using an app on their smartphones, within a specified urban range, and may park the cars in any place (if permitted) upon completion of use, without returning the cars to a basic station. Car2go (affiliated to Daimler) and DriveNow (affiliated to BMW) are two leading companies that adopt the second mode, and use cars that occupy small parking areas, including Smart and MINI. 
To regulate the car sharing industry, Germany promulgated the Car Sharing Preference Act, which was the first federal-level legislation on car sharing and came into effect in September 2017. This act discussed the impact of car sharing on traffic and the environment in detail, providing a legal basis for the promotion of the free flow of shared cars. Related data shows that each shared car serves to replace 20 private cars nearby, and the popularization of car sharing helps emancipate public spaces in cities effectively [3].

\subsection{Car sharing in Japan}

In comparison with the market share of Japanese automobiles in the global market, car sharing is relatively underdeveloped in Japan. Although a few car sharing companies have emerged in Japan in the recent past, their brand influence and market share are far lower than those of companies in Europe and America, such as Uber. This is mainly due to the perfect and convenient public transport system, as well as legal and policy control in Japan [4]. Two main modes for car sharing operate in Japan, namely, time-sharing and use sharing. Time-sharing means that the owners of cars provide their cars to users for driving. In Japan, time-sharing is regulated by the car lease industry. Use sharing means that the owners of cars not only provide their cars, but also provide driving services for users. In Japan, use sharing is regulated by the taxi industry.

Car sharing is regulated rigorously in Japan. First, dual management is exerted over the operating companies and cars in the car lease industry, which time-sharing falls under. In this case, the companies that are previously engaged in car lease must obtain a business license, use various IT means to manage the positions of shared cars, and ensure that the shared cars are parked in special parking spots. This implies that in order to meet regulatory requirements, the car lease companies must provide the shared cars with parking places that are 1.5 to 3 times as large as their previous ones. Obviously, this brings about a rise in their operating costs. Second, dual management is exerted over the operating companies and car drivers in the taxi industry, which use sharing falls under. Even Uber, an industry leader in Europe and America, has to carry out car sharing indirectly by cooperating with traditional taxi companies in Japan's main cities, and is only allowed to carry out car sharing directly in the governmentally designated trial areas. A conservative industrial policy primarily explains why car sharing is relatively underdeveloped in Japan.

\subsection{Car sharing in China}

When compared with other countries, car sharing was initiated relatively late (in 2013) in China, but developed quickly in the subsequent years. With rapid development of the electric automobile industry and an upsurge of Internet-based start-ups, car sharing has become a new breakthrough point in the sharing economy. Governments attach more importance to car sharing, and many automobile manufacturers, car leasing companies, and venture companies have successfully entered the car sharing industry. According to the statistics from the Innovation Research Center for Automobile Industry in the North China University of Technology, by the end of 2016, car sharing was carried out in more than 60 cities in China. There are 20 cities that each have more than 1000 cars available for sharing, and there are totally more than 40000 cars available for sharing across China [5]. Table 1 presents the development status of typical car sharing companies in China. By 2017, more enterprises set foot in car sharing, more cities were covered, and more cars were available for sharing. The number of cars available for sharing has reached 100000 across China. In terms of the quantity of cars available for sharing, China exceeds other countries significantly. Today, China has become a late-coming leader in the field of car sharing.

\section{Car sharing will promote transformational development of China's automobile industry}

The automobile industry is an important pillar of the national economy and is also an important force in promoting the new round in the scientific and technological revolution and industrial transformation. In accordance with Medium and Long-term Development Planning on the Automobile Industry, building an automobile power is the ultimate goal of China's automobile industry. With the new round in the automobile revolution, the development of automobiles takes on some new characteristics, including low carbon, electric driving, networking, intelligence, and sharing. Among these characteristics, sharing is universally believed to be one of the main development trends because sharing is beneficial in the promotion of the transformation and upgrade of the automobile industry, and thus, working toward accomplishing the ultimate goal of turning China into an automobile power as early as possible.

These new characteristics are not isolated from each other, but rather, interact with each other. Low carbon is an external requirement that must be met in the increasingly severe energy and environmental situation. Electric driving represents a fundamental change in the driving mode of automobiles and promotes the transformational development of the entire automobile industry and the upgrading of automobile technologies. The Internet of Things gave birth to the new pattern of "Internet plus automobile," and the interconnection of automobiles is also an essential condition for sharing and intelligence. Intelligence represents an inevitable future trend in automobiles, as it will become the core field of industrial competition and an essential characteristic of prospective automobiles.

Sharing is not only a business pattern, but also represents a prospective mode of travel. Generally, sharing is an inevitable 
Table 1. Development status of typical car sharing companies in China.

\begin{tabular}{|c|c|c|c|}
\hline Operator & Entry time & Main cities allowed & Scale \\
\hline Gofun & February 2016 & $\begin{array}{l}\text { Tier- } 1 / 2 \text { cities, including Beijing, Chengdu, } \\
\text { Wuhan, Xiamen, Ningbo, Fuzhou, Tianjin, and } \\
\text { Hefei }\end{array}$ & More than 20 cities, 15000 cars available for sharing \\
\hline Evcard & July 2013 & Shanghai, Beijing, Wuxi, Lishui, Changzhou & $\begin{array}{l}32 \text { cities, } 6600 \text { business points, and } 25000 \text { cars available for } \\
\text { sharing }\end{array}$ \\
\hline Pand-Auto & $\begin{array}{l}\text { November } \\
2015\end{array}$ & $\begin{array}{l}\text { Chongqing, Hangzhou, Chengdu, Jiyuan, } \\
\text { Zhengzhou }\end{array}$ & Six cities, 2100000 users, and 10000 cars available for sharing \\
\hline TOGO & July 2015 & Beijing, Shanghai, Shenzhen, Guangzhou & 6000 cars available for sharing \\
\hline Yiduyongche & April 2015 & Beijing, Taiyuan, Nanchang & $\begin{array}{l}11 \text { cities, more than } 600000 \text { registered users, more than } 1500 \\
\text { cars available for sharing, and more than } 500 \text { business points in } \\
\text { Beijing }\end{array}$ \\
\hline Bageshare & December 2015 & Beijing, Tangshan, Guangzhou, Tianjin, Langfang & Eight cities, free return of cars in Miyun District (Beijing City) \\
\hline
\end{tabular}

development trend in automobiles. The joint development of sharing and other new characteristics will also promote the accelerated realization of other new characteristics. In addition, sharing can penetrate into and integrate with other new characteristics (including low carbon, electric driving, networking, and intelligence) to give birth to new industrial forms. Understanding and leading this new business mode correctly is of great importance to turning China into an automobile power.

\subsection{Car sharing is an important pathway to low carbon development}

Low carbon emission of automobiles is a major means of satisfying the current traffic needs in China while responding to the severe energy and environmental crisis. China has become the world's largest greenhouse gas emitter, and China's carbon dioxide emissions per unit of GDP are higher than those of developed countries. In China, the existing huge car ownership and the continuous increase in car ownership puts tremendous pressure on energy supply, the environment, and traffic. This is mainly embodied in three aspects:

First, energy consumption of automobiles is confronted with a severe situation. In 2017, China's dependence on foreign oil is as high as $67.5 \%$ and at least $50 \%$ of crude oil is finally consumed by motor vehicles. In China, automobiles are the largest consumers of oil. This has posed a great threat to China's energy safety.

Second, automobile exhausts have become a major source of air pollution in China. According to the China Vehicle Emission Control Annual Report in 2017, promulgated by the Ministry of Environmental Protection, China ranked the first, globally, in terms of production and sale of motor vehicles for eight consecutive years by the end of 2016. Further, the report noted that automobile exhausts have become a major source of air pollution in China and are an important reason for fine particulate pollution and photochemical smog pollution in China. Therefore, it is a matter of urgency to control and prevent air pollution from rising as a result of automobile exhausts. In particular, automobile exhausts are the major source of haze pollution in the automobile-dense cities (for example, Beijing, Shanghai, and Shenzhen). Third, traffic jams are a prominent problem in urban traffic, and urban traffic is confronted by the increasingly severe difficulties in traveling, parking, and traffic disorders. This brings about great inconvenience in people's daily lives, causes huge pressure, and impacts urban traffic management adversely. Traffic jams incur substantial social costs. It is preliminarily estimated that traffic jams cause economic losses to the tune of nearly one trillion yuan annually, in China. Urban traffic jams have become a severe problem that restricts economic development, reduces the quality of people's lives, and weakens economic vitality.

To address various automobile-related problems, car sharing provides a new solution leading toward healthy and sustainable low carbon development. Due to its unique advantages, car sharing has a good effect in relieving traffic jams, improving travel efficiency, reducing road wear and air pollution, and lowering energy dependency. A high degree of car sharing is of great importance to overall social development.

\subsection{Car sharing provides an important market for electric automobiles}

The electric automobile industry is an important industry specified in the "Made in China 2025" strategy. In recent years, China has invested funds to the tune of nearly 100 billion yuan to support the development of the electric automobile industry and has implemented many local supporting policies. The intention is to ensure that the annual production or sales quantity of new-energy automobiles will reach 2000000 by 2020, and account for at least $20 \%$ of China's total production or sales quantity of automobiles by 2025 . Initially, electric automobiles were mainly applied in the field of public traffic, namely, urban buses and taxies. When compared with oil-fired automobiles, electric automobiles have various deficiencies. Users of electric automobiles have no use experience available for reference, so they lack confidence in using the vehicles. Thus, the popular- 
ization of new-energy automobiles calls for a new breakthrough point, especially in the use of private cars. Car sharing offers an important way to popularize electric automobiles. This is mainly due to the following reasons:

First, car sharing can rid users of various worries. Car sharing is primarily characterized by short distances, high frequency of use, and time-based charge. To a certain extent, this serves to overcome the deficiencies of electric automobiles, such as, for example, short continued driving distances and high prices.

Second, car sharing helps users gain experience in and develop the habit of using electric cars. Electric automobiles are obviously different from oil-fired automobiles in terms of the mode of use, so that they will overturn the use habits of some users. Car sharing provides a new channel to experience this type of new product, and helps users get familiar with and even develop an affinity for electric cars, thereby transforming the universal distrust in electric cars among consumers.

Third, car sharing can help operating enterprises acquire feedback and comments from users on the use of electric cars. According to user comments, operating enterprises may upgrade their products as quickly as possible.

\subsection{Car sharing will boost the popularization and application of automobile networking}

Networking mainly means that automobiles are integrated with the Internet. Thus, automobiles can be operated using the Internet as a means, and become an online mobile terminal. Shared cars can provide users with diverse functions (for example, voice navigation, recreation and entertainment, and local services), and also become the ports of big data collection for passengers. Car sharing is an important breakthrough point for the Internet of Vehicles due to the following reasons:

First, sharing of new-energy cars has an inherent advantage with respect to the Internet of Vehicles. The Ministry of Industry and Information Technology demands that all new-energy automobiles, especially those used for public services, should provide long-term, stable, and continuous network connection and data collection functions. Shared automobiles are a major source of public service automobiles in the future and need to provide the most basic networking services and functions.

Second, from the end-consumer perspective, users of shared cars are primarily of younger generations, who usually seek a sense of freshness and fashion. According to a survey conducted by the Society of Automotive Engineers of China in Beijing and Shenzhen in 2017 on male and female respondents (accounting for $62 \%$ and $38 \%$, respectively), by age, the users of shared cars are dominated by young people. In Shenzhen, the users aged between 26 and 30 accounted for $53.5 \%$, and in Beijing, the users aged below 40 accounted for $94.2 \%$. By profession, users of shared cars are dominated by white-collar workers, technical personnel, and college students. These groups universally look forward to the convenience brought about by networked automobiles. In response to such needs, manufacturers and operators of shared cars will launch cars that are better networked to provide new driving experiences for users, thereby overcoming the bad experiences of insufficiency of driving space (note that electric cars are usually small).

Third, from the perspective of industry development, car sharing will promote the development of the Internet of Vehicles industry in China because of the large demand for intelligence technologies and the global industry layout in the future. At present, many Chinese enterprises have set foot in the Internet of Vehicles industry, for example, Feezu and Baojia are two technology providers in this industry. The Internet of Vehicles industry involves a variety of roles and has a long industrial chain. In two fields (including connection services and manufacturing), the Internet of Vehicles industry provides users with underlying technologies and solutions, such as, for example, monitoring of automobile interiors, automobile localization, data collection, and intelligent operation of master control parts. The Internet of Vehicles is also an important realm in which China's automobile industry will accomplish the "from big to strong" goal.

\subsection{Car sharing is the main carrier and application scenario of automobile intelligence}

Intelligent automobiles are capable of sensing, calculating, and decision-making. Automatic drive is the main goal of automobile intelligence. Through the integration of various technologies (including artificial intelligence, advanced algorithms, and computer systems), automobiles will be driven safely and reliably, without manual intervention. Today, automobile intelligence and automatic drive are becoming popular topics.

For a long period of time, China's automobile industry has lagged behind those of other developed countries. Automobile intelligence provides a great opportunity for China's automobile industry to overtake those of developed countries. In recent years, a number of excellent Internet companies have emerged in China, such as, Alibaba, Baidu, and Tencent. They have accumulated rich experience in big data and cloud computing, and actively enter into the automobile industry. Moreover, Chinese users show a great interest in intelligent cars, and actively purchase intelligent cars. All of these provide great support for the development of autonomous cars. Therefore, automobile intelligence and automatic drive provide important breakthrough points in upgrading China's automobile industry.

Car sharing is mainly confronted with the following problems: the scale of cars available for sharing is limited and the use of shared cars is not quite convenient. In the future, breakthroughs in the service bottleneck call for breakthroughs in the automatic drive technologies. Automatic drive, when combined with the Internet of Vehicles, will enable automobiles to complete various functions automatically, such as, driving to the 
locations of users, being recharged, being fed with oil, and finding parking spots. Moreover, the maturity of automatic drive technologies calls for good and suitable application scenarios at a certain scale. Before automatic drive is totally accepted by private consumers, car sharing becomes a good carrier for automatic drive technologies.

\section{Existing problems and measures regarding the development of car sharing in China}

Overall, car sharing is still at its initial stages in China, and its development is confronted by severe challenges. First, car sharing is highly uncertain because it is very susceptible to policy orientation and governmental supervision. In 2017, the Ministry of Transport promulgated the Guidelines on Promoting the Healthy Development of the Rental of Compact and Mini Cars, but no specific implementation scheme is available. Car sharing has been carried out in a few cities, but no official documents have been systematically presented in support of the development of car sharing. Second, operating costs are quite high. The acquisition cost per shared car is usually above 100000 yuan, implying an asset-heavy investment. Third, supporting measures (for example, license quota, car acquisition, policy subsidies, parking places, and charging facilities) are yet to be perfected further.

To accomplish a scale effect, car sharing still calls for progress and breakthroughs in policy support, governmental supervision, technological upgrades, and fine operation. In view of this, this paper presents the following suggestions:

\subsection{Attach great importance to car sharing, with an eye on building an automobile power}

Car sharing represents a prospective travel mode and is supposed to have bright market prospects. Car sharing is beneficial in the promotion of low carbon development, electric driving, networking, and intelligence in the automobile industry. In a new round of great reforms in the automobile industry, car sharing will help China accomplish the goal of overtaking the automobile-advanced countries in a roundabout manner, upgrade the automobile industry, and turn itself into an automobile power.

Car sharing presents an important direction for the strategy of building an automobile power. Therefore, car sharing should be planned and implemented in light of a top-level design, and in conjunction with the "Made in China 2025" strategy, Internet power strategy, and medium and long-term development planning in the automobile industry. To address various problems faced by car sharing, it is necessary to learn from the experience in the popularization of new-energy automobiles, urban planning, construction of parking lots, planning and construction of charging piles, and to strengthen the top-level design in the de- velopment of car sharing and overall planning of the associated industries.

\subsection{Carry out incentive policies, and render greater support} to car sharing

Governments should fully realize that car sharing represents a developmental trend in future urban public traffic, and a high degree of car sharing serves to relieve various prominent problems, for example, traffic jams. The development of car sharing is also of strategic significance to the deep integration of the automobile industry and traffic, environmental protection, and technological development. Therefore, it is necessary to support the development of car sharing as an essential project of urban traffic management.

Supporting policies should focus on the pain-point issues on the development of car sharing. For example, the parking of shared cars calls for active governmental intervention. In the urban centers where parking places are in short supply, public parking lots should give priority to the parking of shared cars. For example, Car2go and Drivenow have been granted "super parking licenses" in permitted cities, allowing users to park shared cars as needed and to take and return shared cars at anytime.

4.3 Increase the license quota moderately, and grant more licenses

In some tier-1 cities, the primary challenge to the development of car sharing usually lies in the limited lease quota. Shared cars are mainly sourced through three channels: lease with license, license lease only, and cooperation with complete automobile manufacturers. Some car leasing companies are not granted any lease quotas, so their operating cars are totally or partly leased from the companies with some granted quotas. Meanwhile, some companies transfer their lease quotas to other companies. This brings about an imbalance in resource allocation.

In view of this, governments should address the restrictions on the lease quotas properly, allow companies to apply for lease quotas freely to a certain extent, and regulate and allocate the lease quotas according to actual operation status. To allocate lease quotas correctly, the car sharing companies should be appraised in the following areas: commitment to developing car sharing, enterprise scale and market share, daily use ratio of shared cars, technology-leading degrees, and customer satisfaction. The appraisal indexes should reflect the operation performance of dominant car sharing companies faithfully and should be carried out.

As an independent third party, governments should advocate a fair and orderly competition, build a favorable industrial environment, and punish vicious competitors severely. Meanwhile, 
governments should also take measures to prevent monopoly and ensure full competition, thus promoting healthy development of the car sharing industry.

\subsection{Build car sharing platforms and provide data resource support for them}

The platforms of existing car sharing companies are usually independent of each other and cannot be interconnected or interworked. In this context, it is recommended that governments encourage companies to develop public platforms for car sharing, thereby enabling users to know the operation status of the cars concerned, attaining a real-time response between cars, charging piles, and parking lots, and accomplishing large-scale operations quickly. Due to the network effect, such public platforms will appeal to more and more users, and governments can also regulate the shared cars more effectively. Through open tendering, such public platforms can select qualified enterprises with technical qualifications and operation experience. Then, governments should regulate the operation of such public platforms, and determine the service charges of such public platforms.

Governments can encourage the opening of certain data resources to support the operation of the car sharing system. To ensure the safety of shared cars, car sharing companies need to assess the credit standing of users. To this end, the concerned governmental agencies need to render necessary support, and share the rule-breaking information on cars with the car sharing companies registered in the public platforms. The intent is to perfect the credit rating system of users in the car sharing system, and help car sharing companies reduce their operation risks.

\section{Conclusions}

Overall, car sharing is an irreversible trend, represents the main direction in the new round of automobile revolution, and will make a great impact on the development of automobiles and even the entire society. China is presented with a great opportunity to turn itself into an automobile power. The rapid development of car sharing not only presents a great opportunity for China, but also allows it to overtake the automobile-advanced countries in a roundabout way. On the way to becoming an automobile power, it is imperative that China should give full play to its own advantages, plan the automobile industry scientifically, and seize the commanding height for the development of car sharing. Car sharing is an overturning economic pattern, so its rapid development will bring about unordered market sprawl and new surplus productivity and make a huge impact on the existing industrial pattern. Moreover, its rapid development will make a non-negligible impact on the existing urban traffic structure. In view of this, it is imperative that China should take precautions against the possible risks arising from the development of car sharing.

\section{References}

[1] Cai Y J, Huang L J. Car sharing, detonating a new round of disruptive business revolution [M]. Beijing: Publishing House of Business Management, 2015. Chinese.

[2] Roland B. 2018 Analysis and forecast report of China's car share travel market [R]. Shanghai: Roland Berger Management Consultants, 2017. Chinese.

[3] Feng X J, Gao S. See Germany and the United States how to standardize the development of shared cars $[\mathrm{N}]$. Nanjing Daily, 2017-8-22(A09). Chinese.

[4] Tian H. The Japanese policy is prudent, balancing the interests of all parties (sharing the car overseas) [N]. People's Daily, 2017-0713(22). Chinese.

[5] Ji X H, Xu Y, Qian W Y. It was born earlier than a shared bike, but why shared vehicles are not popular with the public? [J]. Automotive Business Review, 2017, 10(6): 212-214. Chinese. 